\section{Impact of Weather Changes and Human Visitation on the Behavior and Activity Level of Captive Humboldt Penguins}

\author{
Jiawei Zhang ${ }^{1,2}$, Thomas Quirke', Shibao Wu ${ }^{2 *}$, Shaoshan $\mathrm{Li}^{2}$ and Fidelma Butler ${ }^{1}$ \\ ${ }^{1}$ School of Biological, Earth and Environmental Sciences, Distillery Fields, North Mall, \\ University College Cork, Ireland \\ ${ }^{2}$ SCNU-UCC Joint Laboratory for Ecology and Environmental Science, No.55, \\ Zhongshan Avenue West, Tianhe District, School of Life Science, South China Normal \\ University, Guangzhou 510631, P.R. China
}

\begin{abstract}
A B S T R A C T
This paper describes an assessment of the Impact of weather changes and human visitation on behavior and activity level of Humboldt penguin (Spheniscus humboldti) in captivity. The study is based on activity time-budgets from a flock of over 20 birds at Fota Wildlife Park, Cork, Ireland, gathered during daytime observations over a six month period. The results show that penguins spent most of the daytime in stationary, terrestrial locomotion, preening and swimming modes of behavior, and swimming activity increased on rainy days. Peak activity took place from 16:00 to 17:00 hours, especially before and after feeding. The behavior of penguins was significantly affected by the number of visitors, and locomotion, preening, feeding and attention to visitors were positively correlated with the number of visitors. There is further interaction with visitation levels under different weather conditions. Visitors offer another positive environmental enrichment for this group of penguins and in turn, these penguins at Fota Wildlife Park are considered to have a high educational potential. Some suggestions about captive management and future research are also proposed.
\end{abstract}

\begin{tabular}{l} 
Article Information \\
Received 27 December 2019 \\
Revised 21 February 2020 \\
Accepted 13 April 2020 \\
Available online 12 February 2021 \\
Authors' Contribution \\
\hline JZ designed the experiments, collected \\
and analysed the data and wrote the \\
manuscript. TQ helped in designing \\
the experiments. SW and SL funded \\
and supervised the project, and \\
reviewed the paper. FB communicated \\
with the zoo and revised the paper. \\
Key words \\
Visitor effect, Animal welfare, \\
Educational significance
\end{tabular}

\section{INTRODUCTION}

A nimal welfare, i.e. meeting a captive animal's environmental needs, has received much attention as an important aspect of biodiversity conservation. Various factors threaten the welfare of captive animals in artificial habitats (Scarlata et al., 2013), hence one of the crucial goals of zoos around the world is to improve the health and welfare of animals kept in non-native climates (Howell-Stephens et al., 2012). Captive animals in zoos and wildlife parks play important roles in education, research, and genetic diversity conservation (Poli and McPhee, 2001). Zoos should consider which animals to display based on their educational value, and the animals that most interest visitors and that visitors spend the most time watching may have the highest education potential (Moss and Esson, 2010).

Some potential stressors, such as insufficient environmental enrichment and improper interaction with visitors, may limit captive animals' natural behavior (Scarlata et al., 2013; Khonmee et al., 2014), thus environmental

\footnotetext{
Corresponding author: wushibao@163.com 0030-9923/2021/0002-0591\$9.00/0 Copyright 2021 Zoological Society of Pakistan
}

enrichment and visitor interactions are considered substantial factors affecting zoo animals (Swaisgood and Shepherdson, 2005; Hosey, 2008). Numerous experts and scholars have made detailed studies and records on the former. In comparison, relatively few publications have explored the impact of visitors on animal welfare, even though this relationship has been studied for more than 40 years. When animals are exhibited in zoos, long exposure to humans may result in a predominantly negative, neutral, or positive influence of the human-animal relationship (HAR) (Hosey, 2008).

Not all visitors have a negative impact on wild animals, which can also become habituated to the presence of humans (Burger and Gochfeld, 2007). Some wild penguins are reported to be affected by certain negative human behaviors, but human effects are not entirely unfavorable, and "well-behaved" visitors have little effect on penguins' reproductive behavior (Nimon et al., 1996). In the process of raising animals in captivity, it is possible to encourage natural behavior and motivate captive animals to live like wild animals. For example, breeders can increase penguin swimming time by feeding them in the water (Swaisgood and Shepherdson, 2005). Social behavior, such as vocalization or contact with other penguins, is thought to be beneficial for breeding and for 
adaptation to the environment (Thumser et al., 1996). Some research suggests that certain penguins abandon their nests or progeny when humans approach; human and aircraft disturbances, for example, threaten the population growth of Adelie penguins (Pygoscelis adeliae) (Wilson et al., 1991). Other studies have shown that Magellanic penguins (Spheniscus magellanicus) do not abandon their nests at the approach of humans (Yorio and Dee, 1992), and some African penguins (Spheniscus demersus) are less alert after contact with humans (Van Heezik and Seddon, 1990). Some research shows that the presence of human visitors leads to a decrease in pool use by captive African penguins however, with prolonged exposure, African penguins gradually become used to humans (Ozella et al., 2015). Thereafter, the presence of a large number of visitors promotes greater behavioral diversity and increases penguin pool use. Collins et al. (2015) also found a positive correlation between pool use by penguins and the number of visitors, but the causal direction of these associations has not been determined.

The Humboldt penguin (Spheniscus humboldti) is listed as a vulnerable species on the International Union for Conservation of Nature (IUCN) Red List (IUCN Red List, 2016-10-01). Reports show only 32,000 mature Humboldt penguins in the world and that this population is declining because of food shortages, entanglement in fishing lines, and natural disasters (Culik and Luna, 1997; Cheney, 1998; Culik et al., 2000). Due to the shortage of wild resources and the need to protect biodiversity, captive breeding is one of the best ways to preserve Humboldt penguins. However, captive Humboldt penguins are highly susceptible to fungal and aspergillus infections (Bunting et al., 2009), and the breeding success rate of this species in captivity is only half that in the wild (Blay and Cote, 2001). Unlike the breeding season of Emperor penguins (Aptenodytes forsteri) living in the Antarctic, that of Humboldt penguins is difficult to predict (Williams, 1995). During the breeding season, Humboldt penguins engage in group activities and cooperative hunting (Penguin Taxon Advisory Group, 2003). They usually hunt in cold water. Unlike other penguins, which dive deep to catch prey, Humboldt penguins typically catch food on short dives of up to 30 meters. They also intermittently dive as deep as 60 meters, which enables them to sense and acquire prey more easily (Wilson et al., 1989). The main swimming behaviors of Humboldt penguins are surface swimming, underwater swimming, and porpoising (Penguin Taxon Advisory Group, 2003). They also preen themselves in the water. At Marwell Zoo in Winchester, UK, staff have observed Humboldt penguins spending most of the day resting by the pool rather than swimming in it (Clarke, 2003). When visitors are present, the penguins swim more actively (Condon et al., 2003; Collins et al., 2015).

Captive animals are often affected by microclimate conditions, which may differ from those of their natural habitats. Changes in weather, for example, are closely related to animal reproduction; random changes in rainfall in dry and wet tropical areas of northern Australia can change the birth rate of various organisms, including snakes (Liasis fuscus, Acrochordus attenuurae), crocodiles (Crocodylus porosus), and wallabies (Macropus agilis) (Shine and Brown, 2007). Changes in weather can also affect the weight and energy consumption of captive birds; both have been found to increase slightly on rainy days. Changes in penguin behavior are determined by multiple variables, including weather. As weather cannot be controlled for captive penguin populations kept outdoors, it can be difficult for penguins to adapt to zoo or park environments (Morgan and Tromborg, 2007).

Behavioral diversity is an overall indicator of animal welfare, and greater behavioral diversity is thought to facilitate the treatment of animal diseases and inhibit their transmission (Carlstead and Shepherdson, 2000). As a result, many zoos and aquariums, including Fota Wildlife Park in Cork, Ireland, have developed extensive strategies to increase penguin activity through changing feeding practices and adding enrichment equipment (Taylor and Leonard, 2001; Swaisgood and Shepherdson, 2005; Larson, 2012). However, the effect of human presence on penguins that experience regular and prolonged exposure to tourists (HAR) cannot be ignored (Hosey, 2008).

At Fota, unlike some other zoos and aquariums, the penguins live in the open air, where they are affected by natural weather patterns. Additionally, due to the lack of glass or other solid barrier between humans and penguins, tourists' voices and objects can be directly transmitted to penguins, thus they are more susceptible to human influence. We conducted this study to explore which behaviors of Fota's penguins are influenced by natural and human factors, whether the presence of humans is conducive to improving the behavioral diversity of penguins, and whether an adequate balance is struck between protecting the penguins from the stressors of captivity and providing educational opportunities for zoo visitors. To this end, we explored the following questions:

1. What is the range of behavior patterns of captive Humboldt penguins?

2. Is their behavior pattern affected by factors such as weather and the number of visitors and how?

3. Discuss the kind of penguin behavior preferred by visitors and the educational potential of captive penguins. 


\section{MATERIALS AND METHODS}

Study area and penguins

The study was carried out at Fota Wildlife Park (FWP) situated on the outskirts of Cork city, Ireland. FWP was established in 1983 as a joint project of the Zoological Society of Ireland (ZSI) and University College Cork (UCC). FWP keeps a colony of 26 Humboldt penguins, all born and raised in captivity. Penguins were reared in a $1,900 \mathrm{~m}^{2}$ enclosure that includes a $680 \mathrm{~m}^{2}$ brackish, partially tidal pool with artificial nest areas constructed of stone. Penguins were fed twice daily, at 10:45 hours and 16:00 hours. Keepers disperse fish in ponds or directly feed penguins in artificial caves depending on the season.

Table I. Descriptions of behavioral activities of Humboldt Penguins at Fota Wildlife Park.

\begin{tabular}{|c|c|}
\hline Behaviour & Description \\
\hline Stationary & Not moving while Standing up or lying down \\
\hline Locomotion & Moving on dry land, walking or running \\
\hline Preening & Feather scratching, trimming or shaking \\
\hline Affiliative & $\begin{array}{l}\text { Engage in positive social behavior with anoth- } \\
\text { er penguin, to bring into close association or } \\
\text { mating }\end{array}$ \\
\hline Agonistic & $\begin{array}{l}\text { Engage in negative social behavior with anoth- } \\
\text { er penguin, staring, biting, and attacking }\end{array}$ \\
\hline Feeding & $\begin{array}{l}\text { Catching fish in the pool or receiving fish from } \\
\text { keepers }\end{array}$ \\
\hline $\begin{array}{l}\text { Attention to } \\
\text { visitors }\end{array}$ & $\begin{array}{l}\text { Playing, watching or walking to visitors. Such } \\
\text { as visitors are Shouting, shaking the bottle, } \\
\text { straw or feather to attract the attention of } \\
\text { penguins }\end{array}$ \\
\hline $\begin{array}{l}\text { Attention to } \\
\text { keeper }\end{array}$ & $\begin{array}{l}\text { Playing, chasing or interacting with the keep- } \\
\text { ers, most occur before feeding }\end{array}$ \\
\hline Vocalization & $\begin{array}{l}\text { Calling to protect territory, quarrel with other } \\
\text { individuals, or make calls before eating }\end{array}$ \\
\hline Surface swim & Swimming on the surface of the pool \\
\hline $\begin{array}{l}\text { Underwater } \\
\text { swim }\end{array}$ & $\begin{array}{l}\text { Dive into the water and swim under the } \\
\text { surface }\end{array}$ \\
\hline Porpoising & $\begin{array}{l}\text { Jump vertically into the water or swim up and } \\
\text { down }\end{array}$ \\
\hline Preening pool & Trim the feathers in the water \\
\hline Swimming & $\begin{array}{l}\text { Including surface swim, underwater swim, } \\
\text { porpoising and preening pool }\end{array}$ \\
\hline
\end{tabular}

\section{Data acquisition and analysis}

Behavior was sampled by one observer using instantaneous scan samples (Altmann, 1974) between 10:00 and 17:00 hours in 2018 from January to July. According to the visitation and the weather, we selected data from 2 to 3 days per week (include busy weekends and free weekdays) for analysis. The behavior and the number of visitors and penguins was recorded every two $\mathrm{min}$ for $30 \mathrm{~min}$ followed by a rest period of $30 \mathrm{~min}$.

Fourteen behavioral states were recorded (Table I). Each behavior was defined using operational methods. Human animal interactions (HAIs) were recorded when the penguins reacted to either the visitors or the keepers. Scan data were used to investigate differences among all scanned samples under dry and wet weather conditions and in the presence of different number of visitors at different times of the day (Thumser et al., 1996).

The data were entered into Microsoft Excel 2010 and SPSS 19.0. Microsoft Excel 2010; Origin Pro 8.0 and Sigma Plot 12.5 were used to construct figures and graphs.

In SPSS, we used a one-way analysis of variance and Spearman rank correlation analysis to analyze scan sample data.

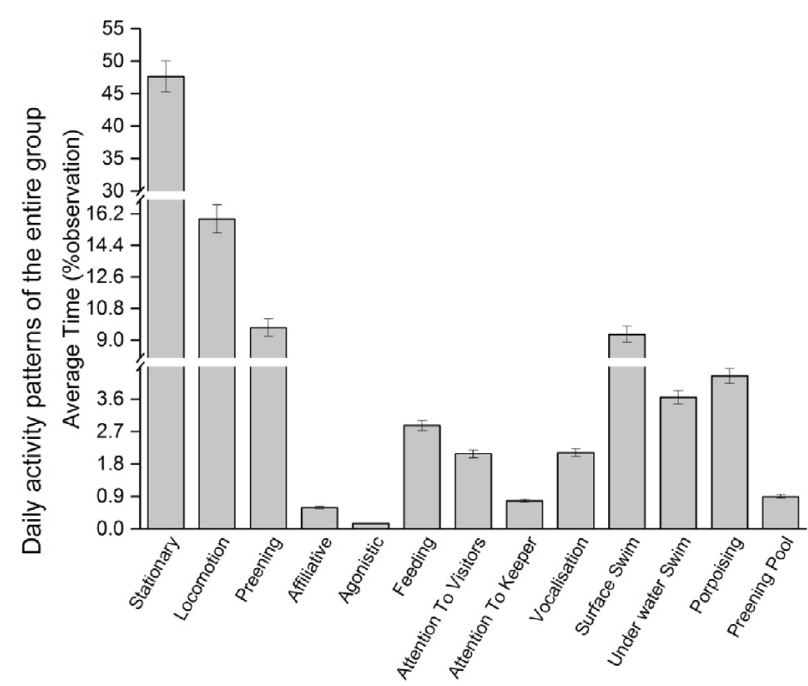

Fig. 1. Daily activity patterns of the entire group of Humboldt Penguins calculated as percentage of time spent observing the behavior of Humboldt penguin during scan sampling over the entire study period at the Fota Wildlife Park. (Mean \pm Standard Error).

\section{RESULTS}

\section{Activity patterns}

The number of individual animals in the study ranged from $n=5-26$ per scan.

As shown in Figure 1, there were significant differences in the amount of time penguins spent engaging in different activities; most time spent in stationary, locomotion, and swimming behaviors. Surface swimming accounted for more than half of all swimming behavior, while underwater 
swimming and porpoising were less common. The smallest percentage of time was spent preening on the side of the pool. However, preening in general did account for a large proportion of penguin behavior. We also recorded a small amount of vocalization behavior. Penguins at Fota are fed twice a day, and each feeding lasts for about 5-10 min, accounting for $2.87 \%$ of total behavior. Feeding benefits captive animals by allowing them to devote less time in searching for and procuring food than they would in the wild. We also recorded a small number of affiliative and agonistic behaviors among penguins. The penguins were generally very friendly to one another, with agonistic behavior being very rare. Penguins attention to visitors and keepers was recorded separately; these behaviors usually occurred before feeding.

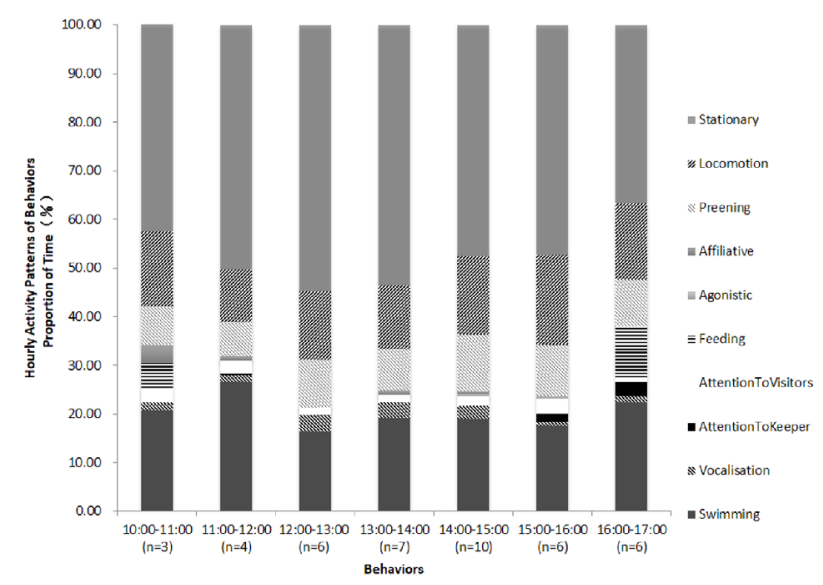

Fig. 2. Hourly activity patterns of penguin behaviors between 10:00 and 17:00 from scan data. Descriptive time budget $(n=44)$.

\section{Time budgets}

During the $7 \mathrm{~h}$ period from 10:00 to 17:00 behaviour, behavioral patterns changed significantly with the time of day (Fig. 2). Generally, penguins were relatively active outside the nest in the morning, became less active in the afternoon, preferring to stay in the nest or lie on the ground outside (although small number of subjects were observed to swim or engage in stationary behavior in the water), and increased their activity again around feeding time (16:00 $\sim$ 17:00). Swimming was recorded across the day but with peaks as a post-feeding behavior. Penguins rest between feeding times during which periods they engage in preening and lying on the bank. Socialization occurs at this time accompanied by affiliative behavior and vocalization. It is worth noting that total activity increased during the feeding period, and the activity time between 10:00 11:00 and $16: 00 \sim 17: 00$ was $63.36 \%$ and $57.17 \%$, respectively.
From 16:00 to 17:00, feeding behavior accounted for $10.81 \%$ of the hour, whereas during the earlier feeding at 10:00-11:00, feeding behavior accounted for 5.59\% of the hour. Swimming behavior increased during the feeding periods and after the morning feeding, between 11:00 and 12:00.

\section{Influence of weather}

There was a clear difference in penguin behavior in wet and dry weather (Fig. 3). There was no obvious difference in locomotion, but penguins engaged in stationary behavior $3.65 \%$ less in wet weather than in dry weather. Swimming, preening, and vocalization behaviors increased in wet weather by $4.6 \%, 1.5 \%$, and $1 \%$ respectively. However, feeding and attention to visitor behaviors were more frequent in dry weather, increasing by $1.32 \%$ and $1.68 \%$, respectively. Visitors also showed distinct behavioral patterns on wet and dry days (Fig. 4). In dry weather, visitors are more likely to speak or shout when watching the penguins, while in the wet weather, the proportion of people watching penguins quietly increased.

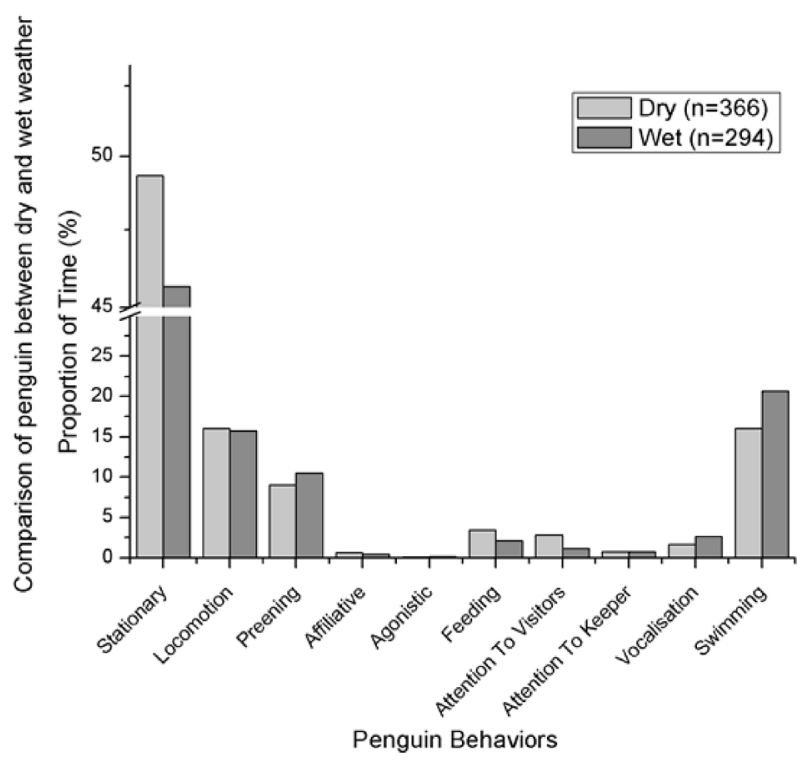

Fig. 3. The effect of weather on the behavior of penguins as a group in Fota Wildlife Park; comparison of behaviors observed during wet $(n=294)$ and dry $(n=366)$ weather conditions.

\section{Interactions between visitors and penguins}

In order to explore the effects of visitor number on penguin behavior, the mean number of observations per visitor category was divided into three categories: no visitors present; $1-10$ visitors; and $>10$ visitors (Fig. 5). The incidence of locomotion and preening increased with 
increasing number of visitors but not significantly. Feeding time was an obvious attraction for visitors as evidenced by the high incidence of this behavior when visitor numbers were high. Human animal interactions also increased with high visitor number when penguins showed a higher incidence of paying attention to visitors. The incidence of swimming and vocalization was greatest in the absence of visitors and declined when visitors were present. These relationships are further seen in scatter grams of the hourly number of visitors plotted against the hourly incidence of behaviors, in particular the increased attention penguins paid to visitors when visitor numbers were high (Fig. 6). It shows a linear regression of penguin behaviors ( $y$-axis) against the number of visitors observed in half an $\mathrm{h}$ ( $x$-axis). The slope of stationary behaviors is close to zero (0.0157); thus, the occurrence of stationary behavior showed little relationship to the presence or number of human visitors. Locomotion, feeding, and preening behaviors rose with increased number of visitors, and the upward trend of the "attention to visitors" behavior is obvious. Vocalization and swimming behaviors declined as the number of visitors increased.

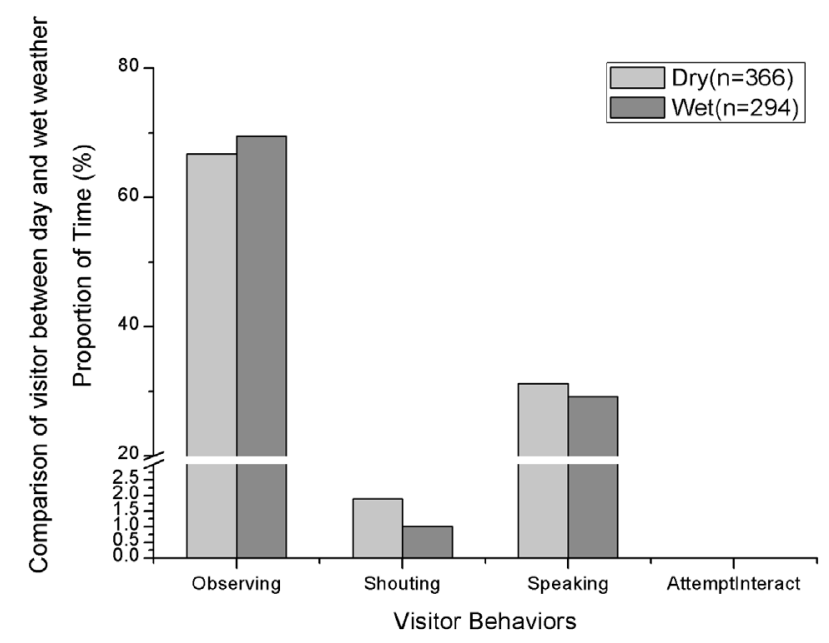

Fig. 4. The effect of weather on the behavior of visitors in Fota Wildlife Park: comparison of human behavioral patterns during wet $(n=294)$ and dry $(n=366)$ weather conditions.

We used SPSS 19.0 to analyze correlations between the number of visitors and seven common behaviors (Table II). Analysis of the scanning data showed that five kinds of behavior were significantly correlated with the number of visitors. Locomotion, feeding, preening and attention behaviors to visitors are significantly correlated with increasing number of visitors, while the incidence of swimming significantly declines with the increasing number of visitors (Table II).
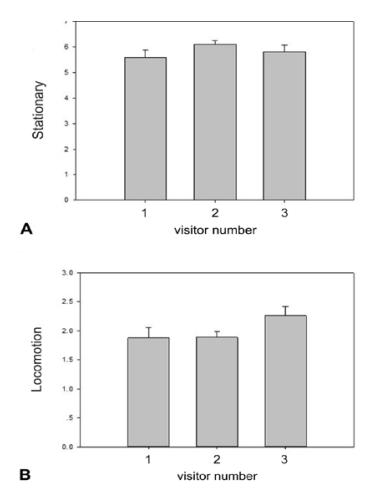

B
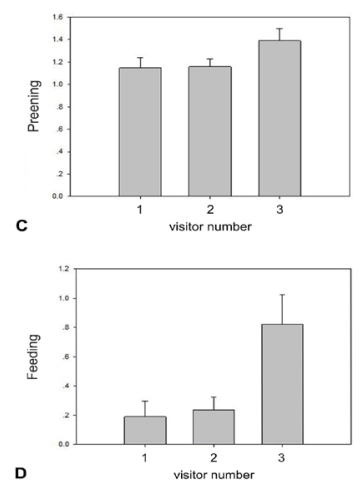

D
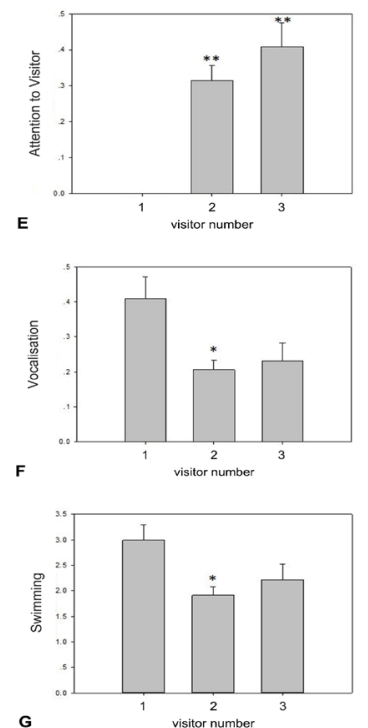

$$
\begin{aligned}
& \text { Number of Visitors } \\
& \begin{array}{l}
1=\text { no visitor } \\
2=1-10 \text { visitors } \\
3=>10 \text { visitors }
\end{array}
\end{aligned}
$$

Fig. 5. Effect of number of visitors on the behavior of penguins as a group in Fota Wildlife Park: a comparison of penguin behavior in the presence of no visitors $(\mathrm{n}=$ $164), 1-10$ visitors $(n=349)$, and $>10$ visitors $(n=147)$. Mean behavior is based on data from each scan. * indicates a significant correlation $(\mathrm{p}<0.05)$; $* *$ indicates a highly significant correlation $(\mathrm{p}<0.01)$. 


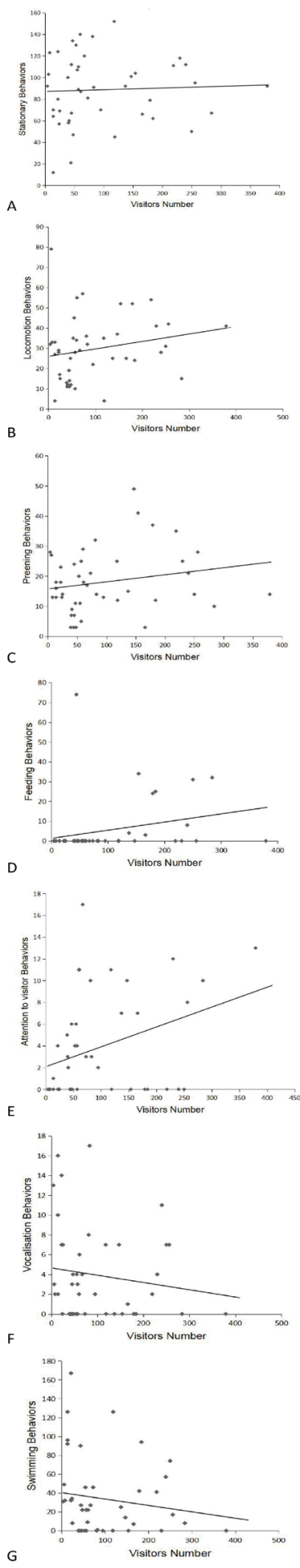

Fig. 6. Scatterplots of effect of visitor numbers on penguin behavior. The x-coordinate of each point is the number of visitors in a given hour, and the $y$-coordinate is the incidence of a given behavior in the same hour. The mean behavior values are based on scan data from each hour $(n=44 h)$.
Table II. Correlations between visitor numbers and several common behaviors of Humboldt penguins. * indicates a significant correlation $(p<0.05)$; ** indicates a highly significant correlation $(p<0.01)$.

\begin{tabular}{lllll}
\hline & Average & $\begin{array}{l}\text { Standard } \\
\text { deviation }\end{array}$ & T & P \\
\hline Visitor number & 6.524 & 7.080 & 1.000 & 0.000 \\
Stationary & 5.912 & 3.098 & 0.200 & 0.608 \\
Locomotion & 1.974 & 1.940 & $0.104^{* *}$ & 0.007 \\
Preening & 1.206 & 1.294 & $0.084^{*}$ & 0.030 \\
Feeding & 0.356 & 1.816 & $0.133^{* *}$ & 0.001 \\
Attention to visitors & 0.258 & 0.704 & $0.154^{* *}$ & 0.000 \\
Vocalization & 0.262 & 0.618 & -0.065 & 0.095 \\
Swimming & 2.249 & 3.486 & $-0.079^{*}$ & 0.043 \\
\hline
\end{tabular}

Both humans and animals feel the effects of weather. In order to examine the human animal interactions under different weather conditions we considered these relationships in dry and wet conditions (Fig. 7). Locomotion, preening, feeding, and attention to visitor behaviors increased with visitor number under both wet and dry weathers. Vocalization decreases in dry and wet weather as visitor number increases. Swimming behavior showed no obvious changes associated with visitor numbers in wet weather but decreased in dry weather with increased visitor numbers. The number of initial feeding, attention to visitors, and vocalization behaviors differed significantly depending on the weather, and in wet weather feeding behavior increased significantly with increased visitor numbers.

\section{DISCUSSION}

Activity patterns and time budgets

Stationary, locomotion, preening, and swimming behavior were the most commonly observed behaviors of penguins in this study. We often observed the same behavior being performed simultaneously by several subjects, both in and out of the nest. Locomotion and diving into the water are often synchronized between individual penguins. Some penguins were observed to remain alone for short periods of time. Some subjects seemed to prefer to remain near the visitor fence, engaging in locomotion, standing still or preening. Stationary behavior, which we suspect is related to penguins' thermoregulation, accounted for a large proportion of time. However, relatively speaking, this is a very active group of penguins. This group of penguins enjoys swimming, and according to Larson (2012) penguins spend more time in swimming pools than on land. 


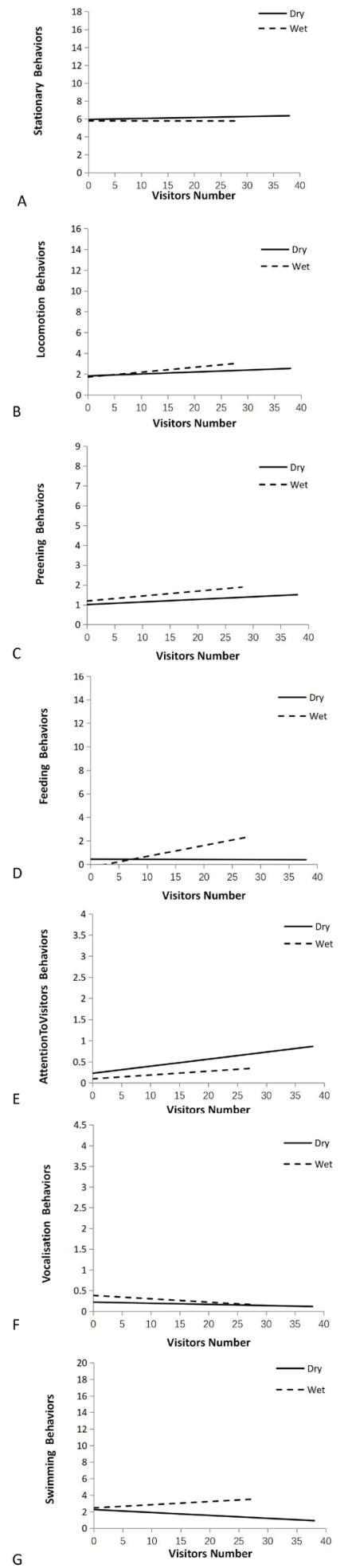

Fig. 7. Comparison of regression equations for the effect of visitors on penguin behavior in wet and dry weather. The mean behavior values are based on data from each scan $($ dry $=366$ wet $=294)$.
However, in this study, the penguins spent more time on land than in the water. Other bird species kept at Fota Wildlife Park frequently fly or jump over the fence into the penguin enclosure, but penguins and other birds were not found to attack or avoid each other during the observation period. We speculate that different bird species have become habituated to each other through long exposure. However, it is interesting to note that when birds of other species were vocalizing, the penguins would sometimes join in as if echoing their calls. We did not observe any significant instances of stereotyped behavior such as in situ rotation or over-preening during the observation period (Lumeij, 2008).

The Humboldt penguins observed in this study were most active between 10:00 and 11:00 and 16:00-17:00, before and after feeding. Peak activity occurred between 16:00 and 17:00, when more visitors were present. Feeding benefits captive animals, which would need to spend a lot of time searching for food in the wild (Hennick and Culik, 2005). However, regular feeding also changes the natural habits of captive animals, and we observed significant effects on swimming, locomotion, and maintenance behavior before and after feeding. Wild Humboldt penguins tend to live in densely populated communities. Feeding captive penguins in the water promotes natural behavior, which is considered an indicator of positive behavior (Swaisgood and Shepherdson, 2005). During in-water feeding, keepers scattered food into the pool, requiring penguins to swim large distances to obtain their food, so feeding time had a larger effect on the percentage of time spent in the water than did the time of day (Fig. 2). Penguins needed to swim to locate food that was scattered in the water or that fell to the bottom of the pool, extending the feeding time. Fast swimming and jumping benefit penguin health (Merritt and King, 2005). Swimming is stimulated after feeding as well; increased pool usage and engaging in preening behavior, both in water and on land, were also observed to increase after feeding. Pool use is positively correlated with the hatching rate, and the increase in activity due to in-water feeding observed here may increase the rate of reproduction (Blay and Cote, 2001). Wehnelt (2003) found that most agonistic behavior in penguins was related to food competition, but we did not observe any such behavior in this study, probably because there was always sufficient food for the entire population, so competition for food was unnecessary.

The influence of weather on penguin behavior and humanpenguin interactions

In total, 660 scanning samples were recorded, 294 of which recorded rain, snow or hail, accompanied by wind and dark clouds Outdoor temperatures were $2-12^{\circ} \mathrm{C}$. 
Because wild Humboldt penguins engage in fewer activities during winter, when body temperature regulation is an important consideration, their behavior in summer is more diverse (Nagy, 1984). Our study, conducted in winter and spring, likely did not reflect their behavior throughout the year. Future research should explore seasonal changes in captive penguin behavior.

In this study, penguins were more active during wet than during dry weather (Fig. 3). The number of penguin movements and use of pools increased significantly, from $16.04 \%$ to $20.64 \%$, during rain, snow, or hail, when penguins would jump into the pool one by one, swim fast in the water, flip and jump rapidly, and preen more frequently (Figs. 3 and 7). Humboldt penguins are very well adapted to water and must maintain the insulation capability of their feathers through daily preening and seasonal molting. Although Christopher found that maintenance behavior was more frequent in dry than in wet weather (Christopher, 2008 ), in this study, preening was $1.50 \%$ more frequent in wet weather than in dry weather. This may have been because preening during the January-May molting season significantly changes the time penguins spend in the water (Ozella et al., 2014), or the increase in molting-related thyroid hormones may lead to a change in behavioral diversity. In wet weather, feeding behavior increased significantly with increased number of visitors (Fig. 7). The presence of visitors may make penguins more excited to eat, although other possible explanations have not been excluded. In dry weather, the penguins spent more time stationary and in locomotion, and affiliative and agonistic behaviors, and attention to visitors increased significantly (Figs. 3 and 7). Penguins were more attracted to people at times when penguin activity was generally high. In wet or cold weather, the number of visitors dropped significantly (Fig. 4). Tourism depends on a range of climate variables, and changes in temperature, precipitation, and humidity affect visitor numbers.

\section{Educational potential of human-penguin interactions}

In this study, penguins engaged in more locomotion, preening, and feeding behaviors when more than 10 visitors were present (Fig. 5). Stationary behavior increased significantly, to an average of $6.10 \%$ of the time budget, when a small number of visitors was present, and decreased to an average of $5.81 \%$ when the number of visitors exceeded 10 (Fig. 5). It may be that when small numbers of visitors are present, most penguins (aside from those standing next to the visitor fence) are not greatly affected; when the number of visitors is large, the stationary penguins become more active and pay attention to visitors. Condon et al. (2003) showed that in the presence of visitors, the number of penguins in the pool increased, and the prevalence of resting behavior decreased, indicating that visitors had a beneficial effect on penguin behavior. Swimming and vocalization behaviors declined when there were small number of tourists present, which may also have been affected by weather factors; as the number of visitors increased, the penguins' swimming and vocal behavior increased slightly. When the number of visitors was more than zero, we found no increase in penguins' use of pools, presumably because only small number of people visited the zoo during cold weather (Fig. 4). Condon et al. (2003) found that the presence of visitors had a positive impact on the swimming behavior of Humboldt penguins at Chester Zoo in the UK. The approach of humans can interfere with seabird predation behavior (Beale and Monaghan, 2004), but we did not find that to be the case in the present study. We were not able to observe many instances of misbehavior by zoo visitors, but when visitors did disturb the penguins, we saw no appreciable change in penguin behavior. Nor did we observe any signs of penguins attacking visitors or displaying aversion to visitors by changing direction, for instance. When visitors shouted, penguins paid significantly more attention to them, sometimes gazing at the visitors and walking around.

As the number of visitors increased, we observed significantly more locomotion, feeding, and preening behaviors (Figs. 6 and 7). Stationary and affiliative behaviors also displayed an upward trend. The penguins at Fota Wildlife Park do not display any evident vigilance against visitors, and increased visitor numbers positively affected their behavioral diversity. Captive birds may be more tolerant of visitors. All of Fota's Humboldt penguins were born in captivity. They are likely to have become habituated to the presence of humans and not to view visitors as potential predators (Beale and Monaghan, 2004). Naturalistic animal exhibits provide shelter that animals can use to avoid contact with tourists, lessening the impact of visitors on animals (Blaney and Wells, 2004). The penguins at Fota have a long history of exposure to humans and can choose either to avoid people if they so desire, or interact with them, when the presence of tourists is another form of environmental enrichment (Nimon and Daliziel, 1992).

Swimming behavior, as seen in Figure 6, was negatively correlated with visitor numbers. A possible explanation for this behavior is that penguins swam much more on wet days, while the number of tourists decreased when the weather was rainy (Fig. 4). Tourists were less active on rainy days, perhaps because cold weather inhibited their activity or because penguins were more active, and tourists were content to watch without interfering (Figs. 4 and 7). Foraging behavior declined in wet weather (Fig. 3), presumably because rainy days are often cloudy and dark, 
and environmental light affects foraging behavior (Mori, 1999). However, wet weather accompanied by an increase in visitors boosted penguin feeding behavior (Fig. 7). This correlation may act in both directions; visitors are more likely to linger to watch penguins forage for food, and penguins may also become more excited as the number of visitors increases. Moreover, Ozella et al. (2015) measured the fecal glucocorticoid metabolite (FGM) of African penguins, found no changes in penguins' adrenocortical hormone activity associated with the number of visitors. As a group, birds are less negatively stimulated by visitors than are other captive animals (Moss and Esson, 2010).

We found that increased visitation had no significant effect on penguin swimming behavior in wet weather, whereas swimming behavior decreased with increased visitor numbers in dry weather (Fig. 7). In the present study, wet weather may have had more influence on swimming activity than did visitor numbers. On rainy or snowy days, penguins were more active, but the number of visitors decreased. Penguins like to swim in cold weather, but tourists are less likely to go to the zoo on inclement days. On dry days, excluding weather disturbances, the penguins' swimming behavior decreased as the number of visitors increased. The reasons are mainly as follows: First, tourists usually choose to watch penguins at the fence near the dry land part of the penguin enclosure. In dry weather, penguins will notice tourists at the fence or walk towards tourists curiously. Penguins choose to look at visitors and exhibit more plumage, movement, and feeding behavior than they otherwise would. At the same time, pool feeding is also swimming behavior. During feeding, tourists are close to the fence beside the pool, and feeding behavior increases with increased number of tourists. It is also apparent from Figure 5 that the swimming behavior of penguins increased slightly when 10 or more tourists were present compared with swimming behavior when only a few tourists were present. A study by Condon et al. (2003) of 10 captive Humboldt penguins at Chester Zoo in England found that human presence exerted a positive impact on the birds' swimming behavior. Human presence may be a minor factor affecting penguin swimming behavior, but the weather is a far stronger determinant of swimming activity. The observed slight reduction in vocalizations in the presence of visitors may require further study. As penguins are on display year-round in Fota Wildlife Park, they acclimate to visitors and do not view them as potential predators. Appropriate active interactions can be encouraged to satisfy animal welfare requirements.

We conducted a bivariate correlation analysis of the number of visitors and penguin behaviors (Table II) and found a significant positive correlation between preening behavior and the number of visitors $(\mathrm{P}<0.05)$ and a significant negative correlation between swimming behavior and the number of visitors $(\mathrm{P}<0.05)$. Locomotion, feeding, and attention to visitors were significantly positively correlated with the number of visitors $(\mathrm{P}<$ 0.01 ). Penguin behaviors clearly changed as the number of visitors increased. This result reconfirms the previous hypothesis. More visitors are likely to be present when penguins engage in behaviors that tourists find appealing. The maximum number of visitors observed in this study was 38. However, more visitors can be expected at other times of the year, and further research is needed to observe the behavior of penguins when visitors increase above the numbers observed in this study.

Occasionally, Humboldt penguins collect organic materials such as hay and bring them into closed caves. In Clarke's experiment (2003), bottles were filled with water and tin foil and placed on the bottom of pools in penguin enclosures to increase penguins' pool use; the bottles were intended to mimic shining underwater fish scales and thus attract penguins into the pool. Visitors could also use water bottles, feathers, or straw to attract the attention of captive penguins. This interaction, while promoting penguin activity, also increased visitor interest in penguins. The penguins would pick up the straws or feathers in their beaks, then carry them around or bring them to their nests inside caves. During the experiment, aggressive behavior was the most obvious manifestation of adverse reactions in the subjects, but the penguins were not observed to attack the visitors (Anderson et al., 2002). We also noticed that when penguins were fed by an unfamiliar keeper, their behavior was affected. The influence of familiar keepers on penguins may require further research.

Finally, we consider penguins' potential for contributing to visitor education in Fota Wildlife Park. Penguins in aquariums and zoos always attract media attention, and "visitor response" is highly controversial because it may have a positive or negative effect on animal welfare (Hosey, 2000). Zoo management must balance the demands of animal welfare and visitor education (Hosey, 2013). Compared to larger animals, small animals such as penguins may be more aware of human presence (Anderson et al., 2002). The penguins in Fota Wildlife Park are on display to visitors throughout most of the year and are born in captivity, so they are largely habituated to the presence of humans. In contrast to Ellenberg's findings on Humboldt penguins, the penguins did not seem to be terribly sensitive to human presence or behavior (Ellenberg et al., 2007). No penguins attacked humans during the observation period. Visitors are more likely to be attracted to more active or visually appealing animals. In Fota, penguins often engage synchronously in behaviors such as locomotion, feeding, and swimming, during which 
times visitors are more engaged and remain at the penguin enclosure for longer periods. As Fota Wildlife Park aims to promote a naturalistic park-like environment, there are no barriers in the penguin feeding area, aside from the fence. When fewer visitors interact with penguins, they do not display any negative behaviors towards visitors, although they apparently do notice them. Sometimes penguins approach visitors or accept items from visitors' hands with their beaks. Provided that visitors do not violate the rules, which forbid feeding the penguins, allowing penguins to accept straw, hay, or bottles from visitors may promote increased activity and nesting behavior (Dunne, 2015). This study found a positive correlation between the number of visitors and stationary behavior, preening, feeding, and attention to visitors. Tourists attract penguins to land for geographical reasons. Swimming behavior decreased with visitor numbers in dry weather, although swimming depended more on precipitation in wet weather.

Not only does the presence of visitors appear not to be detrimental to penguin welfare; it may in fact encourage active behaviors among Humboldt penguins at Fota Wildlife Park. This finding indicates that the presence of visitors can contribute to improving penguins' welfare. It does not at all violate the original intended educational effect of zoos. Penguins are thus highly useful for visitor education, and human-penguin interactions should be encouraged to provide enrichment for penguins and educational opportunities for human visitors. Rain shelters could be installed in the penguin visiting area to allow visitors to watch penguins swimming in wet weather. Penguins have been observed to linger on the shallow beach and alongside flowing water in their enclosure in Fota Wildlife Park. Further research may be required to understand the reasons for these behaviors.

\section{CONCLUSION}

Through our analysis, we constructed a time budget for the behavior of penguins at Fota Wildlife Park. Peak activity occurred from 16:00 to 17:00, and penguins became more active before and after feeding. As the number of human visitors increased, penguins showed a marked increase in locomotion and preening activity. When the weather was inclement, penguin swimming behavior increased, but the number of visitors decreased. In dry weather penguins paid more attention to tourists and exhibited other behaviors rather than going far away to swim. Weather factors had a greater impact than human presence on penguin swimming behavior. In wet weather, penguin swimming behavior was more affected by precipitation than by the presence of humans. Locomotion, preening, feeding and attention to visitors by penguins were positively correlated with the number of visitors, which may indicate that these behaviors were more attractive to visitors, who prefer that penguins be active, or it may indicate that the presence of visitors contributes to the occurrence of these behaviors because these penguins treat visitors as a form of environmental enrichment. For these reasons, the Humboldt penguin exhibition at Fota Wildlife Park has high educational significance while also satisfying animal welfare needs.

\section{ACKNOWLEDGEMENT}

The authors thank UCC School of Biological, Earth and Environmental Sciences for providing financial support for this project and South China Normal University for funding the international joint training program for top graduate student. The authors thank the staff at Fota Wildlife Park for their support for this project. We are grateful to Professor Paul Giller from School of Biological, Earth and Environmental Sciences, University College Cork (UCC) for his valuable opinions on this study.

\section{Statement of conflict of interest}

The authors have declared no conflict of interest.

\section{REFERENCE}

Altmann, J., 1974. Observational study of behaviour: Sampling methods. Behaviour, 49: 227-267. https://doi.org/10.1163/156853974X00534

Anderson, U.S., Benne, M., Bloomsmith, M.A. and Maple, T.L., 2002. Retreat space and human visitor density moderate undesirable behavior in petting zoo animals. J. appl. Anim. Welf. Sci., 5: 125-137. https://doi.org/10.1207/S15327604JAWS0502_03

Beale, C.M. and Monaghan, P., 2004. Human disturbance: People as predation-free predators. $J$. appl. Ecol., 41: 335-343. https://doi.org/10.1111/ j.0021-8901.2004.00900.x

Blay, N. and Côté, I.M., 2001. Optimal conditions for breeding of captive Humboldt penguins (Spheniscus humboldti): A survey of British zoos. Zoo Biol., 20: 545-555. https://doi.org/10.1002/zoo.10002

Blaney, E.C. and Wells, D.L., 2004. The influence of a camouflage net barrier on the behaviour, welfare and public perceptions of zoo-housed gorillas. Anim. Welf., 13: 111-118.

Bunting, E.M., Abou-Madi, N., Cox, S., MartinJimenez, T., Fox, H. and Kollias, G.V., 2009. Evaluation of oral itraconazole administration in captive Humboldt penguins (Spheniscus humboldti). J. Zoo Wildl. Med., 40: 508-518. 
https://doi.org/10.1638/2009-0045.1

Burger, J. and Gochfeld, M., 2007. Responses of emperor penguins (Aptenodytes forsteri) to encounters with ecotourists while commuting to and from their breeding colony. Polar Biol., 30: 1303-1313. https://doi.org/10.1007/s00300-0070291-1

Carlstead, K. and Shepherdson, D., 2000. Alleviating stress in zoo animals with environmental enrichment. In: The biology of animal stress: Basic principles and implications for animal welfare (eds. G.P. Moberg and J.A. Mench). CABI Wallingord. pp. 337-354. https://doi. org/10.1079/9780851993591.0337

Cheney, C., 1998. The current situation of the Humboldt Penguin in Chile and Peru: a report from the population and habitat viability analysis meeting, part 1. Penguin Conserv., 11: 4-9.

Christopher, N., 2008. Veronica by Nicholas Christopher. Jun 24.

Clarke, A.G., 2003. Factors affecting pool use by captive Humboldt penguins (Spheniscus humboldti). In: Proceedings of the $5^{\text {th }}$ Annual Symposium on Zoo Research. Marwell Zoological Park, Winchester, UK, 7-8th July 2003. Federation of Zoological Gardens of Great Britain and Ireland, London. pp. 190-204.

Collins, C., Quirke, T., Overy, L., Flannery, K. and O'Riorda, R., 2015. The effect of the zoo setting on the behavioural diversity of captive gentoo penguins and the implications for their educational potential. J. Zoo Aquar. Res., 4: 85-90.

Condon, E., Wehnelt, S. and Turner, Z., 2003. The effect of visitors on the behavior of Humboldt's penguins at Chester Zoo. Fed. Res. Newsl., 4: 3.

Culik, B.M. and Luna, G., 1997. Statellite tracking of Humboldt penguins (Spheniscus humboldti) in northern Chile. Mar. Biol., 128: 547-556. https:// doi.org/10.1007/s002270050120

Culik, B.M., Hennicke, J. and Martin, T., 2000. Humboldt penguin (Spheniscus humboldti) outmanoeuvring EI Nino. J. exp. Biol., 203: 23112322.

Dunne, C., 2015. Environmental enrichment for captive humboldt penguin (Spheniscus humboldti). Unpublished bachelor's Thesis. University College Cork.

Ellenberg, U., Setiawan, A.N., Cree, A., Houston, D.M. and Seddon, P.J., 2007. Elevated hormonal stress response and reduced reproductive output in yellow-eyed penguins exposed to unregulated tourism. Gen. Comp. Endocrinol., 152: 54-63. https://doi.org/10.1016/j.ygcen.2007.02.022

Hennicke, J.C. and Culik, B.M., 2005. Foraging performance and reproductive success of Humboldt penguins in relation to prey availability. Mar. Ecol. Progr. Ser., 296: 173-181. https://doi.org/10.3354/ meps 296173

Hosey, G., 2000. Zoo animals and their human audiences: what is the visitor effect. Anim. Welf., 9: 343-357.

Hosey, G., 2008. A preliminary model of humananimal relationships in the zoo. Appl. Anim. Behav. Sci., 109: 105-127. https://doi.org/10.1016/j. applanim.2007.04.013

Hosey, G., 2013. Hediger revisited: how do zoo animals see us. J. appl. Anim. Welf. Sci., 16: 338-359. https://doi.org/10.1080/10888705.2013.827916

Howell-Stephens, J., Brown, J.S., Bernier, D., Mulkerin, D. and Santymire, R.M., 2012. Characterizing adrenocortical activity in zoo-housed southern three-banded armadillos (Tolypeutes matacus). Gen. Comp. Endocrinol., 178: 64-74. https://doi. org/10.1016/j.ygcen.2012.04.003

IUCN red list, http://www.iucnredlist.org/apps/redlist/ details/106003862/0, used 2016-10-01.

Khonmee, J., Brown, J.L., Rojanasthien, S., Aunsusin, A., Thumasanukul, D., Kongphoemphun, A., Siriaroonrat, B., Tipkantha, W., Punyapornwithaya, V. and Thitaram, C., 2014. Gender, season and management affect fecal glucocorticoid metabolite concentrations in captive goral (Naemorhedus griseus) in Thailand. PLoS One, 9: e91633. https:// doi.org/10.1371/journal.pone.0091633

Larson, A., 2012. Development and evaluation of environmental enrichment for captive Humboldt penguins. Bachelor's thesis, Swedish University of Agricultural Science.

Lumeij, J.T., 2008. Foraging enrichment as treatment for pterotillomania. Appl. Anim. Behav. Sci., 111: 8594. https://doi.org/10.1016/j.applanim.2007.05.015

Merritt, K. and King, N.E., 2005. Behavioural sex differences and activity patterns of captive Humboldt penguins (Spheniscus humboldti). Zoo Biol., 6: 129-138. https://doi.org/10.1002/ zoo.1430060204

Morgan, K.N. and Tromborg, C.T., 2007. Sources of stress incaptivity. Appl. Anim. Behav. Sci., 102: 262-302. https://doi.org/10.1016/j. applanim.2006.05.032

Mori, Y., 1999. A note on swimming group size in captive African penguins (Spheniscus demersus) in relation to weather conditions. Appl. Anim. Behav. Sci., 62: 359-364. https://doi.org/10.1016/S0168- 
1591(98)00235-4

Moss, A. and Esson, M., 2010. Visitor interest in zoo animals and the implications for collection planning and zoo education programmes. Zoo Biol., 29: 715-731. https://doi.org/10.1002/zoo.20316

Nagy, J.F., 1984. Heroic destinies in the Macgnímrada of Finn and Cú Chulainn. Z. Celtische Philol., 40: 23-39. https://doi.org/10.1515/zcph.1984.40.1.23

Nimon, A.J. and Dalziel, F.R., 1992. Cross-species interaction and communication: A study method applied to captive siamang Hylobates syndactylus and long-billed corella Cacatua tenuirostris contacts with humans. Appl. Anim. Behav. Sci., 33: $261-272$. https://doi.org/10.1016/S01681591(05)80013-9

Nimon, A.J., Schroter, R.C. and Oxenham, R.K., 1996. Artificial eggs: measuring heart rate and effects of disturbance in nesting penguins. Physiol. Behav., 60: 1019-1022. https://doi.org/10.1016/00319384(96)00079-0

Ozella, L., Favaro, L., Carnovale, I. and Pessani, D., 2014. Pond use by captive African Penguins (Spheniscus demersus) in an immersive exhibit adjacent to human bathers. J. appl. Anim. Welf. Sci., 18: 303-309. https://doi.org/10.1080/1088870 5.2014 .977384

Ozella, L., Anfossi, L., Di Nardo, F. and Pessani, D., 2015. Non-invasive monitoring of adrenocortical activity in captive African penguin (Spheniscus demersus) by measuring faecal glucocorticoid metabolites. Gen. Comp. Endocrinol., 224: 104112.. https://doi.org/10.1016/j.ygcen.2015.06.014

Penguin Taxon Advisory Group, 2003. Spheniscus penguin husbandry manual. Eaza $1^{\text {st }}$ ed.

Poli, R. and McPhee, N.F., 2001. Exact schema theorems for GP with one-point and standard crossover operating on linear structures and their application to the study of the evolution of size. Genet. Progr., pp. 126-142. https://doi.org/10.1007/3-540-453555_11

Scarlata, C., Elias, B., Godwin, J., Powell, R., Shepherdson, D., Shipley, L. and Brown, J., 2013. Influence of environmental conditions and facility on faecal glucocorticoid concentrations in captive pygmy rabbits (Brachylagus idahoensis). Anim. Welf., 22: 357-368. https://doi. org/10.7120/09627286.22.3.357

Shine, R. and Brown, G.P., 2007. Adapting to the unpredictable: reproductive biology of vertebrates in the Australian wet-dry tropics. Philos. Trans. R. Soc. B., 363: 363-373. https://doi.org/10.1098/ rstb.2007.2144

Swaisgood, R.R. and Shepherdson, D.J., 2005. Scientific approaches to enrichment and stereotypies in zoo animals: what's been done and where should we go next? Zoo Biol., 24: 499-518. https://doi. org/10.1002/zoo.20066

Taylor, S.S. and Leonard, M.L., 2001. Foraging trip duration increases for Humboldt Penguin tagged with recording devices. J. Avian Biol., 32: 69-71. https://doi.org/10.1111/j.0908-8857.2001.320413.x

Thumser, N.N., Karron, J.D. and Ficken, M.S., 1996. Interspecfic variation in the calls of Spheniscus penguins. Wilson Bull., 108: 72-79.

Van Heezik, Y. and Seddon, P.J., 1990. Effect of human disturbance on beach groups of Jackass Penguins. S. Afr. J. Wildl. Res., 20: 89-93.

Wehnelt, S., 2003. Agonistic intra and inter specific interactions of two colonies of Waldrapp ibis (Geronticus eremita) housed in mixed species exhibits at Chester Zoo. Res. News Fed. Res. Newsl., 4: 2-12.

Williams, T.D., 1995. The Penguin: Sphenisicidae. Oxford University Press, New York.

Wilson, R.P., Wilson, M.P., Duffy, D.C. and Araya, B., 1989. Diving behavior and prey of the Humboldt penguin (Spheniscus humboldti). Field Ornithol., 130: 75-79. https://doi.org/10.1007/BF01647164

Wilson, R.P., Culik, B., Danfeld, R. and Adelung, D., 1991. People in Antarctica - how much do Adélie penguins (Pygoscelis adeliae) care. Polar Biol., 11: 363-370. https://doi.org/10.1007/BF00239688

Yorio, P. and Dee Boersma, P., 1992. The effects of human disturbance on Magellanic penguin (Spheniscus magellanicus) behaviour and breeding success. Bird Conserv. Int., 2: 161-173. https://doi. org/10.1017/S0959270900002410 